\title{
Hambúrgueres de aparas de jacaré-do-pantanal (Caiman yacare) submetidos a diferentes técnicas de defumação
}

\author{
[Hamburguers from pantanal caiman meat (Caiman yacare) subjected to \\ different smoking techniques] \\ V.R.T. Fernandes ${ }^{1}$, M.L.R.S. Franco ${ }^{1}$, E. Gasparino ${ }^{1}$, A. Tanamati ${ }^{2}$, \\ M.E. Coutinho ${ }^{3}$, K. Bielawski ${ }^{1}$ \\ ${ }^{1}$ Universidade Estadual de Maringá - Maringá, PR \\ ${ }^{2}$ Universidade Tecnológica Federal do Paraná - UTFPR - Campo Mourão, PR \\ ${ }^{3}$ Ibama/RAN - Centro de Conservação e Manejo de Répteis e Anfíbios - Lagoa Santa, MG
}

\begin{abstract}
RESUMO
Avaliaram-se hambúrgueres de aparas de jacaré-do-pantanal (Caiman yacare) quanto à composição centesimal, cor e análise sensorial. $\mathrm{O}$ delineamento foi inteiramente ao acaso, em três tratamentos: $\mathrm{T} 1=$ sem defumação; T2= defumação a quente e T3= defumação líquida, e nove repetições. As aparas foram moídas e condimentadas para o hambúrguer. Os hambúrgueres para defumação a quente foram colocados no defumador $60 \mathrm{~min}$ a $60^{\circ} \mathrm{C}$ com gerador de fumaça por fricção. Foi pulverizada fumaça líquida, sobre os produtos (T3), e estes foram colocados em desidratador por $60 \mathrm{~min}$ a $60^{\circ} \mathrm{C}$. Houve diferença significativa quanto à composição centesimal entre os hambúrgueres defumados, T2 = 43,1\% e $\mathrm{T} 3=$ $60,9 \%$, e verificou-se menor teor de umidade em relação aos sem defumação, 73,3\%. A proteína, 39,9\%, e as cinzas, $6,1 \%$, foram mais altas nos defumados a quente. Os hambúrgueres defumados a quente apresentaram menor luminosidade, 42,05, e maiores valores do croma $a^{*}, 14,65$, e b*, 28,57, em relação aos demais tratamentos. As variáveis sensoriais foram significativas para sabor, textura e aceitação geral. Os produtos defumados a quente apresentaram a pior aceitação. Concluiu-se que a defumação a quente proporciona produtos com menor teor de umidade, com pigmentação mais intensa, porém menos aceitos pelos provadores.
\end{abstract}

Palavras-chave: hambúrguer, defumação, jacaré-do-pantanal

\begin{abstract}
Hamburgers made from minced meat of Pantanal caiman (Caiman yacare) were evaluated for their centesimal composition, color and sensory perception. The experiment was structured in a completely randomized design with three treatments $(T 1=$ no smoke; $T 2=$ smoked with hot smoke and $T 3=$ smoked with liquid smoke), with nine repetitions each. The meat was minced and seasoned for the hamburgers. The hamburgers destined to hot smoking were placed in the smoker $\left(60 \mathrm{~min}\right.$ at $\left.60^{\circ} \mathrm{C}\right)$ with smoke generated through friction. The liquid smoke was sprayed in the samples (T3), next they were placed in dehydrators $\left(60\right.$ min at $\left.60^{\circ} \mathrm{C}\right)$. There was a significant difference in centesimal composition, the smoked hamburgers $(T 2=43.1 \%$ and $\mathrm{T3}=60.9 \%)$ presenting significantly less moisture than non-smoked products (73.3\%). Protein (39.9\%) and ash (6.1\%) were higher for the hot-smoked samples. The hotsmoked hamburgers had less luminosity (42.05) and higher values of chroma a* (14.65) and $b^{*}(28.57)$ than the other treatments. The sensorial parameters evaluated were significant for flavor, texture and general acceptance. The hot-smoked products had the worst acceptance. It was concluded that the hot smoke provided products with less moisture and higher pigmentation, but with less acceptance from the judges.
\end{abstract}

Keywords: hamburgers, smoking, Caiman yacare

Recebido em 24 de novembro de 2011

Aceito em 7 de fevereiro de 2013

E-mail: vrtfernandes@gmail.com 


\section{Fernandes et al.}

\section{INTRODUÇÃO}

O jacaré-do-pantanal (Caiman yacare) é uma ótima fonte de proteína de origem animal para alimentação humana, possui alto valor biológico, alta digestibilidade, baixos valores de colesterol e demonstra potencial tecnológico para a elaboração de derivados (Romanelli et al., 2002). Segundo Vicente Neto et al. (2007), a oferta desse tipo de carne é baixa e os índices de produção são flutuantes. Há uma carência de informações sobre as carnes e os subprodutos de animais silvestres, tanto em relação às características físico-químicas, ao rendimento, às propriedades organolépticas, bem como do processamento da carne e de derivados ou à utilização dos subprodutos.

A exploração sustentável da espécie foi autorizada pelo Instituto Brasileiro do Meio Ambiente e Recursos Naturais Renováveis (Ibama), com base na Portaria $\mathrm{n}^{\circ} 126$, de fevereiro de 1990. A carne é comercializada para restaurantes de carnes exóticas ou butiques de carne, sendo um produto elitizado, e informações sobre suas características e processamento são imprescindíveis para o sucesso da cadeia produtiva, fato que justifica a importância e a necessidade da realização de estudos mais abrangentes, principalmente, na utilização dos cortes de baixo valor comercial, com o intuito de agregar valor à atividade.

O objetivo do trabalho foi avaliar hambúrgueres elaborados de aparas de carne do jacaré-dopantanal submetidos a diferentes técnicas de defumação quanto à composição centesimal, cor e análise sensorial.

\section{MATERIAL E MÉTODOS}

O experimento foi realizado em Laboratório Escola de Tecnologia do Pescado, e as análises de composição centesimal em Laboratório Escola de Alimentos. Foram utilizadas aparas congeladas de jacaré de cativeiro, autorizado pelo Ibama, doadas pela Cooperativa dos Criadores de jacaré-do-pantanal (Coocrijapan), situada na cidade de Cáceres, MT.

Para os hambúrgueres, as aparas foram moídas, condimentadas com $0,1 \%$ de pimenta e $2 \%$ de sal, incluído $10 \%$ de bacon e $3 \%$ de proteína texturizada de soja hidratada. A massa gerada, bem homogeneizada, foi dividida em três tratamentos: $\mathrm{T} 1=$ sem defumação; T2= defumação a quente e T3= defumação líquida. Os hambúrgueres, $70 \mathrm{~g}$, foram moldados com hamburgueira. Para defumação a quente, os hambúrgueres foram colocados no defumador com geração de fumaça por fricção, por $60 \mathrm{~min}$ a $60^{\circ} \mathrm{C}$. Para defumação líquida, foi pulverizada a fumaça líquida Krakismoke FI 9027 Plus $^{\circledR}$ (6:1) sobre os hambúrgueres submetidos ao desidratador por $60 \mathrm{~min}$ a $60^{\circ} \mathrm{C}$.

O combustível utilizado para produzir fumaça foi o caibro $(8 \mathrm{~cm} \times 8 \mathrm{~cm} \times 80 \mathrm{~cm})$ de eucalipto rosa (Eucalyptus globulus Labill) e para manutenção da temperatura, o gás de cozinha. Foram elaborados hambúrgueres que serviram como padrão sem defumação. Depois de elaborados, todos foram congelados a $-18^{\circ} \mathrm{C}$ até o momento de realização das análises.

Para a determinação de composição centesimal, as amostras foram homogeneizadas em multiprocessador até a obtenção de massa homogênea. As análises de umidade e cinza foram realizadas de acordo com a metodologia da Association of Official Analytical Chemists (Association..., 1995). Os teores de proteína bruta foram determinados pelo método semimicro Kjeldahl, descrito por Silva e Queiroz (2002), e para a extração dos lipídios totais empregou-se o método Bligh e Dyer (1959). As análises foram realizadas em triplicata. Para os atributos sensoriais, aplicou-se o teste afetivo de aceitação a 50 provadores não treinados, em pratos codificados e com amostras colocadas de maneira aleatória. Os atributos cor, aroma, sabor, textura, teor de sal, aparência e aceitação global foram avaliados utilizando-se escala hedônica de nove pontos, variando de "gostei muitíssimo", nota igual a 9, a "desgostei muitíssimo", nota igual a 1, sendo a mediana "nem gostei nem desgostei" (Dutcosky, 1996; Monteiro et al., 2005). Os provadores também responderam sobre a intenção de compra do produto oferecido. Para avaliação da intenção de compra, foi utilizada a escala de cinco pontos, na qual cinco representava a nota máxima "certamente compraria" e um representava a nota mínima "certamente não compraria", empregando-se os procedimentos descritos para análise sensorial (Meilgaard et al., 1991; Damásio e Silva, 1996). $\mathrm{O}$ projeto de análise sensorial foi aprovado pelo Comitê de Ética em Pesquisa Envolvendo Seres 
Humanos da Universidade Estadual de Maringá, com base na Resolução $n^{\circ} 196 / 96$, parecer $n^{\circ}$ $149 / 2010$.

A cor dos filés de cauda foi determinada com o auxílio do colorímetro portátil (modelo MiniScan EZ, marca Hunter Lab.), com fonte de luz D65, ângulo de observação de $10^{\circ}$ e abertura da célula de medida de $30 \mathrm{~mm}$, usando-se a escala $\mathrm{L}^{*}$, a*, $\mathrm{b}^{*}$ do sistema CIELab, desenvolvido por Judd e Hunter (Hunter, 1995) e padronizado em 1976. A atividade de água dos hambúrgueres foi determinada utilizando-se o higrômetro.

O delineamento experimental foi inteiramente ao acaso, com três tratamentos e nove repetições. Os resultados foram submetidos à análise de variância, e as médias comparadas pelo teste Tukey, a 5\% de probabilidade (Sistema..., 2000). Para análises estatísticas dos dados sensoriais, utilizou-se o procedimento PROC GENMOD do SAS (Statistical..., 2001), considerando-se a distribuição das variáveis como sendo gama com função de ligação inversa.

\section{RESULTADOS E DISCUSSÃO}

Houve diferença significativa para as análises de composição centesimal (Tab. 1). Os hambúrgueres defumados apresentaram significativamente menor teor de umidade em relação aos sem defumação, $73,3 \%$, porém os submetidos à defumação com fumaça líquida, $60,9 \%$, apresentaram maior teor de umidade que os defumados a quente, $43,1 \%$. Com a redução da umidade, houve concentração dos demais nutrientes nos hambúrgueres elaborados independentemente da técnica de defumação.

O teor de proteína bruta e cinzas foram significativamente superiores para os hambúrgueres defumados a quente comparados aos com fumaça líquida. O regulamento técnico de identidade e qualidade de hambúrguer estabelecido pela legislação brasileira vigente exige teor mínimo de $15 \%$ para proteínas e máximo de $23 \%$ para lipídios (Brasil, 2000). Com relação a esses padrões, todos os hambúrgueres elaborados estavam de acordo com a legislação.

Tabela 1. Valores médios da composição centesimal dos hambúrgueres de aparas de jacaré-do-pantanal (Caiman yacare)

\begin{tabular}{lcccc}
\multicolumn{1}{c}{ Tratamento } & Umidade $(\%)$ & Proteína (\%) & Lipídios (\%) & Cinzas $(\%)$ \\
\hline Sem defumação & $73,34 \mathrm{~A}$ & $19,10 \mathrm{C}$ & $3,91 \mathrm{C}$ & $2,93 \mathrm{C}$ \\
Defumação a quente & $43,14 \mathrm{C}$ & $39,90 \mathrm{~A}$ & $6,26 \mathrm{~B}$ & $6,13 \mathrm{~A}$ \\
Defumação líquida & $60,86 \mathrm{~B}$ & $27,08 \mathrm{~B}$ & $6,71 \mathrm{~A}$ & $4,17 \mathrm{~B}$ \\
\hline CV $(\%)$ & 1,5 & 3,12 & 6,04 & 1,74 \\
\hline \multicolumn{2}{l}{ Letras maiúsculas diferentes na mesma coluna indicam diferença entre valores pelo teste Tukey $(\mathrm{P}<0,05)}$.
\end{tabular}

Segundo Schimidt (1994), a composição nutricional da carne magra corresponde a $75 \%$ de umidade, $20 \%$ de proteína, $3 \%$ de lipídios e $2 \%$ de sustâncias solúveis não nitrogenadas. A composição nutricional dos hambúrgueres elaborados sem defumação apresentou semelhança em relação aos valores de composição química de uma carne magra.

Romanelli et al. (2002) verificaram em hambúrgueres de jacaré-do-pantanal teores de umidade de $75,3 \%$ e $19,4 \%$ de proteína bruta. Esses valores estão próximos aos obtidos neste experimento para os hambúrgueres sem defumação, enquanto para os defumados, independentemente do processo, os teores de umidade foram mais baixos que os relatados por esses autores. Os teores de proteína dos hambúrgueres defumados foram mais altos que os relatados pelos mesmos autores, em razão da desidratação que ocorreu com o processo de defumação independentemente da técnica aplicada.

Para a indústria, os ligantes proteína e/ou gordura adicionados aos hambúrgueres apresentam a vantagem de baratear o custo do produto. $\mathrm{O}$ hambúrguer de algumas marcas existentes no mercado é composto de até $50 \%$ de proteína vegetal ou animal, que é bem aceito pelo consumidor. Pela qualidade nutricional e alta digestibilidade da carne do jacaré-do-pantanal, há a recuperação de proteínas de materiais de descarte e a elaboração de um produto de baixo custo, como é o caso do hambúrguer, pois este se mostra economicamente viável (Romanelli et al., 2002). 
Os teores de lipídios e cinzas dos hambúrgueres a quente foram superiores aos com fumaça líquida (Tab. 1). Com a maior redução da umidade dos hambúrgueres e defumados a quente, houve maior concentração de lipídios e cinzas. Romanelli et al. (2002) realizaram o processamento da carne do jacaré-do-pantanal para hambúrgueres com adição de $20 \%$ de bacon e obtiveram produtos com $4,2 \%$ de lipídios e $1,0 \%$ de cinzas. O teor de lipídio foi próximo aos obtidos nos hambúrgueres sem defumação deste experimento, enquanto os teores de cinzas foram mais altos em todos os tratamentos para os hambúrgueres.

Os valores observados nos nutrientes da composição centesimal foram mais elevados que os encontrados em outros trabalhos, que visavam à produção de hambúrguer e utilizaram outras espécies como matéria-prima. Moura et al. (1998) encontraram valores de 5,1\% para lipídios e $16,9 \%$ para proteína no desenvolvimento do babyburguer, hambúrguer elaborado com carne de búfalo usando-se corte secundário. Arisseto e Polonio (2003), na elaboração de um hambúrguer calabresa, verificaram teor de 7,4\% de lipídios e 18,8\% de proteínas. Entretanto, Mancha (1999) relatou teor de gordura de 1,75\% no desenvolvimento de hambúrguer de carne caprina. Siqueira et al. (2001) verificaram teores de gordura, proteína e umidade na faixa de $2,1-2,6 \%, 17,8-19,5 \%$ e $77,1-77,7 \%$, respectivamente, no desenvolvimento de um hambúrguer bovino de baixo teor de gordura, utilizando-se carne de soja, com o amido modificado e proteína de soja.
Com relação ao teor de cinzas neste experimento, houve grande variação. Salvino et al. (2009), ao fazerem a caracterização microbiológica, físicoquímica e sensorial de hambúrgueres de carne de avestruz (Struthio camellus), elaborados com substituto de gordura, não observaram diferença $(\mathrm{P}>0,05)$ entre as amostras, que variaram de 1,96 a 1,98\%. Fernández-López et al. (2006) relataram valores de $1,9 \%$ e $1,95 \%$ nas amostras de hambúrgueres de avestruz. Todos esses valores de cinzas foram mais baixos que os obtidos neste experimento para aparas de jacarédo-pantanal.

Quanto à coloração, os hambúrgueres defumados a quente apresentaram menor luminosidade que os demais tratamentos (Tab. 2). De acordo com Choubert et al. (1992), com o processo de defumação ocorre a perda de água e, consequentemente, a luminosidade diminui. Este fato pode ser confirmado, pois os teores de umidade dos produtos defumados a quente foram mais baixos que os demais (Tab. 1).

O parâmetro L* luminosidade apresentou valores entre 42,05 e 60,37 para os hambúrgueres. Os sem defumação apresentaram maior luminosidade, ou seja, maior valor de $\mathrm{L}^{*}$, indicando um produto mais pálido ou uma cor mais clara. Os cromas $a^{*}$ e $b^{*}$ foram mais elevados nos hambúrgueres com defumação a quente e significativamente menores nos sem defumação (Tab. 2). O croma b* indica maior intensidade da cor amarela, e o croma $a^{*}$ da cor vermelha. Os defumados a quente apresentaram coloração mais intensa para $o$ amarelo avermelhado quando comparados aos com fumaça líquida.

Tabela 2. Análise de cor dos hambúrgueres de aparas de jacaré-do-pantanal (Caiman yacare)

\begin{tabular}{lccc}
\multicolumn{1}{c}{ Tratamento } & $\mathrm{L}^{*}$ & $\mathrm{a}$ & $\mathrm{b}^{*}$ \\
\hline Sem defumação & $60,37 \mathrm{~A}$ & $1,30 \mathrm{C}$ & $11,44 \mathrm{C}$ \\
Defumação a quente & $42,05 \mathrm{C}$ & $14,65 \mathrm{~A}$ & $28,57 \mathrm{~A}$ \\
Defumação líquida & $53,21 \mathrm{~B}$ & $5,54 \mathrm{~B}$ & $21,24 \mathrm{~B}$ \\
\hline CV $(\%)$ & 7,76 & 16,46 & 6,95 \\
\hline
\end{tabular}

Letras maiúsculas diferentes na mesma coluna indicam diferença entre valores pelo teste Tukey $(\mathrm{P}<0,05)$.

De acordo com Santos Júnior et al. (2009), no desenvolvimento de hambúrguer de carne de ovinos de descarte enriquecido com farinha de aveia, a avaliação do parâmetro $\mathrm{L}^{*}$ apresentou valores entre 43,28 e 51,27, sendo que a formulação adicionada de toucinho possuiu o maior valor de $\mathrm{L}^{*}$, indicando um produto mais pálido. Os valores de a* variaram de 4,38 a 7,8, sendo o menor valor correspondente à formulação com $100 \%$ de carne ovina. Neste trabalho, com as aparas de jacaré-do-pantanal, os valores de croma $a^{*}$ foram significativamente $(\mathrm{P}<0,05)$ mais elevados para o hambúrguer defumado a quente, a luminosidade $\mathrm{L}^{*}$ foi maior 
para o hambúrguer sem defumação, e para hambúrguer com defumação líquida, a luminosidade foi intermediária.

A atividade de água dos hambúrgueres variou de 0,86 defumação a quente a 0,98 sem defumação. Os hambúrgueres defumados com fumaça líquida apresentaram maior atividade de água, 0,90, quando comparados aos defumados a quente. Esses valores coincidem com os resultados de umidade apresentados na Tab. 1, sendo que os hambúrgueres sem defumação apresentaram $73,3 \%$ de umidade, os com fumaça líquida $60,9 \%$, e os defumados a quente $43,1 \%$.
Os parâmetros sensoriais avaliados foram significativos para sabor, textura e aceitação geral para o hambúrguer, sendo que os hambúrgueres sem defumação e os com defumação líquida foram preferidos em relação a esses parâmetros. A defumação não influenciou na cor, aroma, teor de sal, aparência e intenção de compra dos hambúrgueres (Tab. 3). Os hambúrgueres elaborados e submetidos à defumação a quente foram menos aceitos que os hambúrgueres sem defumação e defumados com fumaça líquida.

Tabela 3. Média das características sensoriais dos hambúrgueres de aparas de jacaré-do-pantanal (Caiman yacare)

\begin{tabular}{lccccccc}
\multicolumn{1}{c}{ Tratamento } & Cor & $\begin{array}{c}\text { Aro } \\
\text { ma }\end{array}$ & Sabor & Textura & $\begin{array}{c}\text { Teor } \\
\text { de sal }\end{array}$ & Aparência & $\begin{array}{c}\text { Aceitação } \\
\text { geral }\end{array}$ \\
\hline Sem defumação & 6,78 & 6,68 & $7,40 \mathrm{~A}$ & $7,06 \mathrm{~A}$ & 7,32 & 6,82 & $7,08 \mathrm{~A}$ \\
Defumação a quente & 7,04 & 6,58 & $6,30 \mathrm{C}$ & $5,30 \mathrm{C}$ & 6,64 & 6,64 & $6,33 \mathrm{~B}$ \\
Defumação líquida & 6,96 & 6,84 & $6,88 \mathrm{~B}$ & $6,48 \mathrm{~B}$ & 7,06 & 7,32 & $7,08 \mathrm{~A}$ \\
\hline Significância & $\mathrm{ns}$ & $\mathrm{ns}$ & $* *$ & $* *$ & $\mathrm{~ns}$ & $\mathrm{~ns}$ & $*$
\end{tabular}

ns = não significativo; $* *=$ significância a $1 \% ; *=$ significância a $5 \%$.

Letras maiúsculas diferentes na mesma coluna indicam diferença entre valores pelo teste de Tukey $(\mathrm{P}<0,05)$.

Para o teste de intenção de compra, foi utilizada uma escala estruturada em cinco pontos, em que os julgadores atribuíram notas de 1 (certamente não compraria o produto) até 5 (compraria o produto), não havendo diferença significativa entre os tratamentos, e os valores variaram de 3,02 a 3,80 (tenho dúvidas se compraria). Em relação aos hambúrgueres defumados, $22 \%$ dos provadores, provavelmente, não comprariam o defumado a quente, e $8 \%$ os defumados com fumaça líquida. Já os hambúrgueres sem defumar, $16 \%$ dos provadores, provavelmente, não os comprariam (Fig. 2).

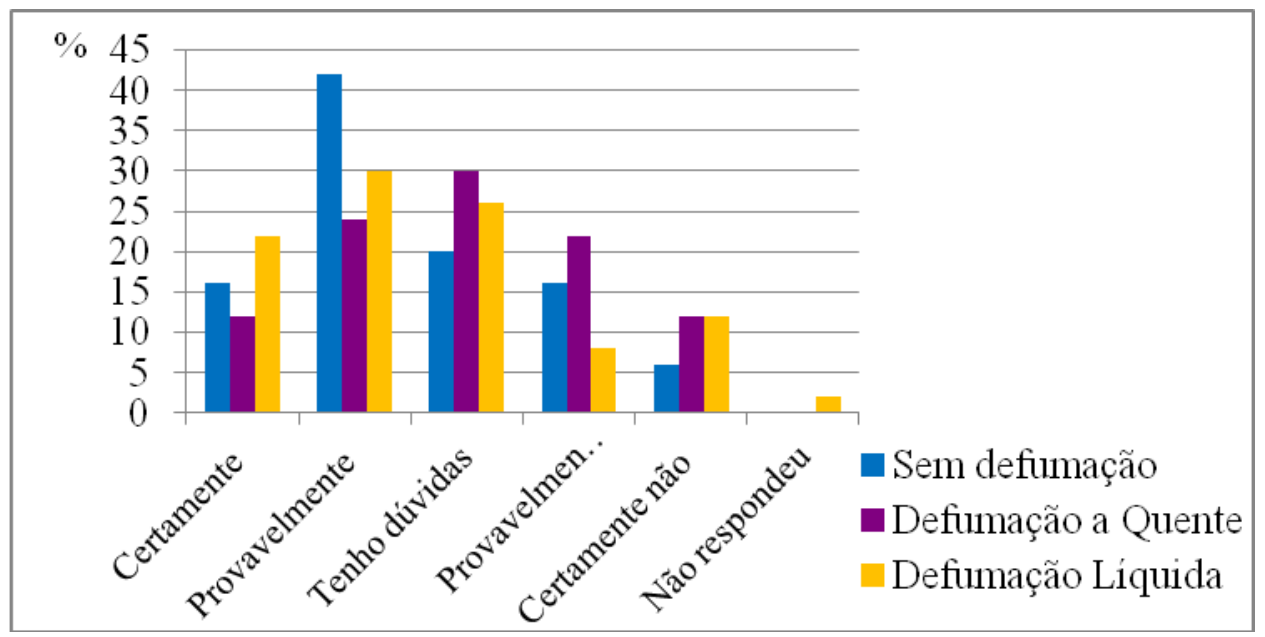

Figura 2. Intenção de compra dos hambúrgueres elaborados de aparas de jacaré-do-pantanal (Caiman yacare). 
Romanelli et al. (2002) avaliaram o hambúrguer elaborado de uma mistura de carne picada de jacaré-do-pantanal, toucinho, ingredientes de cura e especiarias. Os autores verificaram que os hambúrgueres, visualmente, ficaram próximos aos hambúrgueres de frango, porém o aroma não agradou aos provadores. $\mathrm{Na}$ análise sensorial, os autores relataram que o produto foi aceito, mas houve comentários desfavoráveis, como duro e apimentado, então foi modificada a textura adicionando-se $25 \%$ de toucinho suíno. Com a mudança, a análise sensorial mostrou um aumento de, aproximadamente, $17 \%$ na aceitação do produto.

De acordo com Romanelli et al. (2002), os hambúrgueres de jacaré receberam a nota 4,84 , quando foi avaliada sua aceitação global, estando abaixo do encontrado nesta pesquisa. Daigle et al. (2005) realizaram análise sensorial em produtos elaborados com carne de peru pálida, flácida e exsudada (PSE) e hidrocoloides como carragena, colágeno e proteína de soja e não detectaram diferença significativa $(\mathrm{P}<0,05)$ entre os tratamentos. Os autores utilizaram escala hedônica de nove pontos, obtendo escores médios que variam entre seis e sete: gostou ligeiramente e gostou moderadamente.

O hambúrguer é um produto com chances de favorecer a boa prática alimentícia por apresentar alta aceitação, por ser uma carne nutritiva, além de uma opção inovadora no mercado. Também, proporciona a diminuição dos resíduos de descarte, contribuindo para uma prática mais sustentável para o meio ambiente e a atividade.

\section{CONCLUSÕES}

Os hambúrgueres tiveram sabor, textura e aceitação geral característicos do produto e atenderam às necessidades nutricionais de proteína e lipídios, conforme exige a legislação brasileira. Os hambúrgueres defumados a quente apresentaram pior aceitação, portanto pode-se dizer que a aprovação maior ocorreu para os hambúrgueres sem defumação ou com defumação líquida, o que mostra a viabilidade técnica para a elaboração de produtos derivados de carne de jacaré-do-pantanal, por ser uma forma alternativa de consumo.

\section{AGRADECIMENTOS}

Os autores agradecem à Cooperativa dos Criadores de Jacaré do Pantanal (Coocrijapan) pela doação das amostras.

\section{REFERÊNCIAS}

ARISSETO, A.P.; POLLONIO, M.A.R. Desenvolvimento e aceitação das características do hambúrguer tipo calabresa. In: ENCONTRO NACIONAL DE ANALISTAS DE ALIMENTOS, 13., 2003, Rio de Janeiro. Resumos... Rio de Janeiro: ENAAL, 2003. p.133.

ASSOCIATION of official analytical chemistry AOAC. Official Methods of Analysis, 16.ed. Arlington: AOAC International. 1995.

BLIGH, E.G.; DYER, W.J. A rapid method of total lipid extraction and purification. Can. J. Biochem., v.37, p.911-917, 1959.

BRASIL. Instrução Normativa n²0 de 31 de Julho de 2000. Aprova regulamento Técnicos de Identidade e Qualidade de almôndegas, de apresuntado, de fiambre, de Hambúrguer, de kibe, de presunto cozido e de presunto. Diário Oficial [da] República Federativa do Brasil, Brasília, DF, 3 ago. 2000. Seção 1, p.7.

CHOUBERT, G.; BLANC, J.M.; COURVALIN, C. Muscle carotenoid content and colour of farmed rainbow trout fed astaxanthin or canthaxanthin as affected by cooking and smokecuring procedures. Inter. J. Food Sci. Technol., v.27, p.277-284, 1992.

DAIGLE，S.P.; SCHILLING, M.W.; MARRIOTT, N.G. et al. PSE-like turkey breast anhancement throug adjunct incorporation in a chunked and formed deli roll. Meat Sci., v.69, p.319-324, 2005.

DAMÁSIO, M.H.; SILVA, M.A.A.P. Curso de treinamento em análise sensorial. Campinas: Fundação Tropical de Tecnologia "André Tosello", 1996. Apostila.

DUTCOSKY, S.D. Análise sensorial de alimentos. Curitiba: Champagnat, 1996. 84p.

FERNÁNDEZ-LÓPEZ， J.; JIMÉNEZ， S.; SAYAS-BARBERÁ, E. et al. Quality Characteristics of ostrich (Struthio camelus) burgers. Meat Sci, v.73, p.295-303, 2006. 
HUNTER, R.S. The measurement of appearence. New York: J. Willey, 1975. 411p.

MANCHA, M.B.A. Pesquisadora desenvolve hambúrguer de bode. Rev. Nac. Carne, v.270, p.40-41, 1999.

MEILGAARD, M.; CIVILE, G.V.; CARR, B.T. Sensory evaluation techniques. 2.ed. Boca Raton: CRC, 1991. 354p.

MONTEIRO, R.A.; COUTINHO, J.G.; RECINE, E. Consulta aos rótulos de alimentos e bebidas por freqüentadores de supermercados em Brasília, Brasil. Rev. Panam. de Salud Pública, v.18, p.172-177, 2005. Disponível em: <http://www.scielosp.org/pdf/rpsp/v18n3/27666. pdf >. Acessado em: 03 jun. 2011.

MOURA, M.M; AZEVEDO, N.A.A.; LOURENÇO JÚNIOR, J.B. et al. Rendimento e Características Físico-Químicas de "Babyburguer" elaborado com corte secundário de Baby Búfalo. Rev. Nacional da Carne, v.266, p.301-302, 1998.

ROMANELLI, P.F.; CASERI, R.; LOPES FILHO, J.F. Processamento da carne do jacarédo-pantanal (Caiman crocodilus yacare). Ciênc. Tecnol. Aliment., 2002. Disponível em: <http://www.scielo.br/pdf/cta/v22n1/a13v22n1.p df>. Acessado em: 05 fev. 2010.

SALVINO, E.M.; SILVA, J.A.; NOBREGA, E.S. et al. Cracterização microbiológica, físicoquímica e sensorial de hambúrgueres de carne de avestruz (Struthio camellus), elaborados com substituto de gordura. Rev. Inst. Adolfo Lutz, v.68, p.34-41, 2009.

SANTOS JUNIOR, L.C.O.; RIZZATTI, R.; BRUNGERA, A. et al. Desenvolvimento de hambúrguer de carne de ovinos de descarte enriquecido com farinha de aveia. Cienc. Anim. Bras., v.10, p.1128-1134, 2009.
STATISTICAL Analysis Sistem. SAS INSTITUTE. SAS User's guide: statistics. Version 8, SAS Inst., Cary, NC, 2001.

SCHIMIDT, G.R. Comportamiento funcional de los componentes de la carne durante el procesado. In: PRICE, J.F.; SCHWEIGERT, B.S. Ciencia de la carne y de los productos cárnicos. Zaragoza: Editorial Acribia, 1994. $377 \mathrm{p}$.

SILVA, D.J.; QUEIROZ, A.C. Análise de Alimentos: Métodos Químicos e Biológicos. 3.ed. Viçosa: Universidade Federal de Viçosa, 2002. 235p.

SIQUEIRA, P.B.; LEMOS, A.L.S.C.; HARADA, M.M.; ODA, S.H.I. Desenvolvimento e Aceitação de Hambúrguer com Baixo Teor de Gordura. Food Ingred., v.14, p.74-77, 2001.

SISTEMA de Análises Estatísticas. Versão 8.0. SAEG. Viçosa: UFV, 2000. 138p.

USER'S guide: statistics. Version 8.01. Cary, NC: SAS Institute, 2001.

VICENTE NETO, J.; BRESSAN, M.C.; RODRIGUES, E.C. et al. Avaliação físico química da carne de jacaré-do-pantanal (Caiman yacare Daudin 1802) de idades diferentes. Cienc. agrotec., v.31, p. 1430-1434, 2007. Disponível em:

<http://www.scielo.br/pdf/cagro/v31n5/24.pdf>. Acessado em: 15 mai. 2010. 